\title{
Reproductive System Findings Elapsed Time
}

National Cancer Institute

\section{Source}

National Cancer Institute. Reproductive System Findings Elapsed Time. NCI Thesaurus.

Code C162204.

The interval between two reproductive system findings reference time points. 